\title{
Speciation-controlled incipient wetness impregnation: A rational synthetic approach to prepare sub-nanosized and highly active ceria-zirconia supported gold catalysts
}

\author{
Eloy del Río, Diana Gaona, Juan C. Hernández-Garrido, José J. Calvino, Manuel G. Basallote, \\ María J. Fernández-Trujillo, José A. Pérez-Omil, José M. Gatica*
}

Departamento de Ciencia de los Materiales, Ingeniería Metalúrgica y Química Inorgánica, Facultad de Ciencias, Universidad de Cádiz, Campus Río San Pedro, E-11510 Puerto Real (Cádiz), Spain

\section{A R T I C L E I N F O}

\section{Article history:}

Received 4 June 2014

Revised 1 July 2014

Accepted 2 July 2014

Available online 25 August 2014

\section{Keywords:}

Supported Au catalysts

Synthesis

Speciation

Incipient wetness impregnation

CO oxidation

High dispersion

\begin{abstract}
A B S T R A C T
On the basis of calculated thermodynamic species distribution diagrams and by appropriately controlling the $\mathrm{pH}$ of aqueous $\mathrm{HAuCl}_{4}$ solutions, it has been possible to prepare, using a Speciation-controlled Incipient Wetness Impregnation (ScIWI) approach, Au catalysts supported on ceria-zirconia mixed oxides featuring both high gold loadings and excellent metal dispersions. This rational synthesis method is carried out at room temperature. It is both much simpler, in equipment terms, and less expensive than widely used Deposition-Precipitation (DP). Moreover, the use of ScIWI allows overcoming the severe limitations of previously assayed impregnation methods. With this procedure it is possible to prepare active catalysts in $\mathrm{CO}$ oxidation with high efficiency in terms of gold precursor usage, i.e. minimizing Au losses during synthesis. Therefore this, quite amenable, novel strategy for the facile preparation of highly dispersed supported gold catalysts gathers the necessary requirements for both its use at lab scale and an easy scaling-up to industrial levels.
\end{abstract}

๑) 2014 Elsevier Inc. All rights reserved.

\section{Introduction}

Since Haruta reported, by the end of the 1980s, the exceptionally high activity for $\mathrm{CO}$ oxidation of supported gold catalysts prepared by co-precipitation (CP) or Deposition-Precipitation (DP) methods [1-5], catalysis by supported gold nanoparticles (Au-NPs) has become the focus of very intense research [6]. Early insights into the catalytic applications of supported gold [7-9] had already shown that Incipient Wetness Impregnation (IWI) techniques proved unable to prepare catalysts featuring gold particles of only a few nanometers in size. Thus, despite IWI had been successfully used in the synthesis of highly dispersed catalysts of other noble metals, such as Pt, Rh, Pd or Ru, it unavoidably led to Au catalysts exhibiting particles in the $10-50 \mathrm{~nm}$ size range [10]. Although these large particles exhibited a superior chemistry, as bulk Au, for some specific applications [7,8,11-13] their applicability in catalysis resulted limited, since $5 \mathrm{~nm}$ appears to be a critical size for oxidation reactions such as catalytic oxidation of CO at low temperature [14-16].

\footnotetext{
* Corresponding author.

E-mail address: josemanuel.gatica@uca.es (J.M. Gatica).
}

Hydrated $\mathrm{HAuCl}_{4}$ has been the most used precursor of metallic gold. It is widely accepted that the chloride ligands in the coordination sphere of $\left[\mathrm{AuCl}_{4}\right]^{-}$are responsible for the agglomeration of gold, through $\mathrm{Au}-\mathrm{Cl}-\mathrm{Au}$ linkages [17-21], in catalysts prepared by classical impregnation methods. The occurrence of polymerization through Cl-bridging results deleterious not only because it leads to Au-NPs growth, but also because it eliminates mono and binuclear gold-chloro complexes which are considered as the active species in a variety of gold-catalyzed organic reactions [22,23].

In spite of this available knowledge, only a few attempts have been addressed to improve the metal dispersion of supported $\mathrm{Au}$ catalysts using impregnation techniques with this gold precursor [12,24-33]. Among them, Louis et al. [27] reported that $\mathrm{Au} / \mathrm{TiO}_{2}$, $\mathrm{Au} / \mathrm{Al}_{2} \mathrm{O}_{3}$ and $\mathrm{Au} / \mathrm{SiO}_{2}$ catalysts containing $\mathrm{Au}$ particles of small size (3-4 nm) could be prepared using conventional IWI followed, once the support pores were filled with $\mathrm{HAuCl}_{4}$, by two consecutive washing steps with an ammonia aqueous solution. This work was extended to other supports a previous one by Datye et al. [25] who reported that Au particles with an average diameter of $2.4 \mathrm{~nm}$ could be supported on alumina by IWI applying a washing treatment with an aqueous solution of $\mathrm{NH}_{3}$ after impregnation. 
Similarly, Schüth et al. [28] proposed the use of ammonia steam after classical IWI, to prepare $\mathrm{Au} / \mathrm{TiO}_{2}$ catalysts with a very narrow Au-NPs size-distribution (2-4 nm). All these are cases of a twostep synthesis method in which post-treatments provide a route to exchange chloride by ammonia ligands in the coordination sphere of the $\left[\mathrm{AuCl}_{4}\right]^{-}$precursor. Although the effect of these treatments over Au supported on titania, alumina and silica catalysts demonstrated as very effective in overcoming the coalescence of $\mathrm{Au}$, explosive fulminating gold composites may be easily produced $[34,35]$. When this technical complication is considered, this approach does not seem recommendable for an application at the scale of industrial production.

As an alternative, Soares et al. [30] developed the so-called double impregnation method (DIM), which involves the use of two different aqueous solutions, one containing the $\mathrm{HAuCl}_{4}$ precursor, which is impregnated to fill just half the total pore volume (IWI volume), and a $\mathrm{Na}_{2} \mathrm{CO}_{3}$ solution which is added, in a second impregnation step, to completely fill the pores. Using this approach, these authors reported the preparation of $\mathrm{Au} / \mathrm{TiO}_{2}$ catalysts with Au-NPs below $5 \mathrm{~nm}$. Nevertheless, the method led in the case of a $1 \mathrm{wt} \% \mathrm{Au} / \mathrm{CeO}_{2}$ catalyst [36] to a size distribution with gold particles in the $8-13 \mathrm{~nm}$ size range. These results suggest that the DIM procedure, though efficient for $\mathrm{Au} / \mathrm{TiO}_{2}$ catalysts, is not adequate for the preparation of those supported on ceria-based oxides. We should additionally mention that Au loadings of catalysts prepared by DIM rarely exceed $1 \mathrm{wt} \%$.

In [24], Lee et al. used dry and wet impregnation techniques to prepare a series of $\mathrm{Au} / \mathrm{Al}_{2} \mathrm{O}_{3}$ catalysts. They started from a high surface area $\gamma-\mathrm{Al}_{2} \mathrm{O}_{3}$ support and diluted $\left(2.5 \times 10^{-3} \mathrm{M}\right) \mathrm{HAuCl}_{4}$ aqueous solutions whose $\mathrm{pHs}$ were adjusted at values ranging from 5 up to 11 by adding varying amounts of a sodium carbonate solution. Nevertheless, the aged $\mathrm{HAuCl}_{4}$ aqueous solutions were diluted with a very large volume of water before the impregnation step. The authors observed that the final gold loadings of the prepared catalysts were very low, less than $1 \mathrm{wt} \%$, specially in the catalyst prepared using the solution with the highest $\mathrm{pH}$, $\mathrm{pH}=11$, for which the amount of loaded gold was just $0.09 \%$. In spite of such low loadings and the very high surface area of $\gamma-\mathrm{Al}_{2} \mathrm{O}_{3}$, all the prepared catalysts contained large Au particles ( $>6 \mathrm{~nm}$ ).

More recently, another approach was developed by Prübe et al. [32] to synthesize $\mathrm{Au} / \mathrm{Al}_{2} \mathrm{O}_{3}$ systems, starting from a solution of the $\mathrm{HAuCl}_{4}$ precursor in $2 \mathrm{M} \mathrm{HCl}$. Although these authors also ignored the uncontrolled and drastic effects on alumina of the treatments in so strongly acidic conditions, small gold particles (1-2 nm) were only observed by TEM for catalysts with very low metal contents (0.3 wt\%). This procedure has been also assayed to prepare $\mathrm{Au} / \mathrm{CeO}_{2}$ and $\mathrm{Au} / \mathrm{CuO}_{x} / \mathrm{CeO}_{2}$ catalysts but led in these cases to catalysts with very poor Au dispersions and, consequently, low activities in $\mathrm{CO}$ oxidation [37].

In all the studies reported above, $\mathrm{HAuCl}_{4}$ was the gold precursor. In order to avoid gold polymerization through $\mathrm{Au}-\mathrm{Cl}-\mathrm{Au}$ bridges [19], IWI techniques using chloride-free organogold salts have been also assayed [38-40]. Following this strategy, in Ref. [39] the impregnation of $\mathrm{Al}_{2} \mathrm{O}_{3}$ supports with an aqueous suspension of $\mathrm{Au}(\mathrm{III})$ acetate resulted in a catalyst exhibiting a bimodal particle size distribution (small and large Au particles) after calcination at $623 \mathrm{~K}(4 \mathrm{~h})$. Although calcinations at high temperature were necessary to completely remove the carboncontaining species from the Au salt, little attention was paid to sintering of the gold precursors upon these treatments. Moreover, the maximum loading of Au-NPs achievable by this method was limited to about $1 \mathrm{wt} \%$, due to the low solubility in water of $\left[\mathrm{Au}\left(\mathrm{O}_{2} \mathrm{CCH}_{3}\right)_{3}\right]$ commercial precursors.

In summary, with the exception of works which used ammonia post-treatments $[25,27,28]$, which suffer from a high-risk of developing fulminating gold catalysts, all the improved impregnation procedures described above unfortunately fail to provide catalysts featuring both a high Au loading and a high metal dispersion. Consequently, alternative approaches are still necessary.

A strategy yet unexplored consists in combining the use of a chemically well-defined impregnating Au solution, which favors a highly dispersed state, and IWI. Taking into consideration the key influence of $\mathrm{pH}$ on the exact nature of the distribution of $\mathrm{Au}$ species present in $\mathrm{HAuCl}_{4}$ solutions [41], we decided to study the advantages of modifying this speciation before incipient impregnation, by controlling this parameter. We hypothesized that by using solutions with appropriate $\mathrm{pH}$ values, allowed to age during the necessary time to reach thermodynamic equilibrium state, and avoiding any further modification of this $\mathrm{pH}$ during the preparation procedure, it would be possible to favor the interaction of the supports with a major fraction of dissolved gold species containing a low number of $\mathrm{Cl}$ ligands. This would eventually allow us minimizing the occurrence of the $\mathrm{Au}-\mathrm{Cl}-\mathrm{Au}$ bridges considered to lead to poor gold dispersions. Since the basic idea underlying the incipient impregnation process is starting from a solution in which the distribution of $\mathrm{Au}$ species is tailored, we will refer to the method as to ScIWI (Speciation-controlled IWI). Following this approach four different $\mathrm{Au} / \mathrm{Ce}_{0.62} \mathrm{Zr}_{0.38} \mathrm{O}_{2}(\mathrm{Au} / \mathrm{CZ})$ catalysts were prepared starting from $\mathrm{HAuCl}_{4}$ aqueous impregnating solutions with $\mathrm{pH}$ values in the 1-12 range. These supported gold catalysts are compared, in terms of dispersion and CO oxidation activity, with others prepared by double impregnation (DIM) and deposition-precipitation using urea (DPU).

\section{Experimental}

\subsection{Preparation techniques}

\subsubsection{Incipient Wetness Impregnation (IWI)}

A nominal $3 \mathrm{wt} \% \mathrm{Au} / \mathrm{Ce}_{0.62} \mathrm{Zr}_{0.38} \mathrm{O}_{2}$-IWI ( $\mathrm{Au} / \mathrm{CZ}-\mathrm{IWI}$ ) sample was prepared by classical IWI method, i.e. using a $\mathrm{HAuCl}_{4}$ aqueous solution without further $\mathrm{pH}$ modification $(\mathrm{pH}=1) .5 .1 \mathrm{~g}$ of a $68 \mathrm{~m}^{2} \mathrm{~g}^{-1}$ ceria-zirconia mixed oxide, $\mathrm{Ce}_{0.62} \mathrm{Zr}_{0.38} \mathrm{O}_{2}$, (CZ) support were impregnated to pore volume $\left(0.6 \mathrm{ml} \mathrm{g}^{-1}\right.$ of $\left.\mathrm{CZ}\right)$ using a $\mathrm{HAuCl}_{4} \cdot 3 \mathrm{H}_{2}$ O (99.99\%, Alfa Aesar) 0.51 M aqueous solution. This Au solution, with $\mathrm{pH}$ about 1 , was previously allowed to age at room temperature for $30 \mathrm{~min}$.

\subsubsection{Precursor Speciation-controlled Incipient Wetness Impregnation (ScIWI)}

This preparation procedure has been registered in [42]. The 3 wt\% Au/CZ-ScIWI-8 and Au/CZ-ScIWI-12 catalysts were prepared by impregnation to pore volume of the $\mathrm{CZ}$ support using $\mathrm{HAuCl}_{4}$ aqueous solutions with $\mathrm{pH}$ values of 8 and 12, respectively. $\mathrm{pH}$ adjustment was done by adding the appropriate volumes of a $2.5 \mathrm{M} \mathrm{NaOH}$ (Alfa Aesar 98\%) aqueous solution. Considering the results reported in [43] in relation to the kinetics of gold chlorohydroxo complexes hydrolysis, these Au solutions were aged at room temperature for $4 \mathrm{~h}$, and submitted several times to ultrasonic waves (sonolysis) in order to prevent the formation of $\mathrm{Au}(\mathrm{OH})_{3}$ precipitates. Then the impregnating solution was added drop wise to $2.25 \mathrm{~g}$ of the $\mathrm{CZ}$ support at room temperature under continuous stirring.

\subsubsection{Double impregnation method (DIM)}

In this case, Au was loaded, nominal $3 \mathrm{wt} \%$, on the CZ (5 g) support by using a double impregnation method (DIM) following the procedure described by Bowker et al. [30].

After the impregnation step all the samples were repeatedly washed with distilled water to remove remnant chlorides. Then, they were dried overnight in an oven at $373 \mathrm{~K}$, meshed at 
$125 \mu \mathrm{m}$, and stored in the dark under Ar until further use. To avoid the possible influence of daylight, all these processes were carried out in a darkroom. Finally, the as-prepared samples were activated using the following procedure: pretreatment during $1 \mathrm{~h}$, at $473 \mathrm{~K}$ under flowing $\mathrm{O}_{2}(5 \%) / \mathrm{He}$. Then the gas flow was switched to pure He while keeping the temperature at $473 \mathrm{~K}$, for $1 \mathrm{~h}$. Finally the samples were cooled down to room temperature in flow of pure He. In all cases, the heating rate was $10 \mathrm{~K} \mathrm{~min}^{-1}$.

\subsection{Characterization methods}

Chemical analysis of Au loading was performed by inductively coupled plasma atom emission spectroscopy (ICP-AES). The $\mathrm{Cl}$ content was determined by X-ray fluorescence (XRF) using a WD Bruker System ( $4 \mathrm{~kW})$ model S4PIONEER. Nitrogen adsorption experiments at $77 \mathrm{~K}$ of the powder catalysts were performed on a Micromeritics ASAP-2020 instrument to determine the textural properties, specifically, the Brunauer/Emmet/Teller (BET) surface area, pore size and pore volume distributions. The amount of sample used in this study was $200 \mathrm{mg}$. Before measurement, the catalysts were degassed for $2 \mathrm{~h}$ at $473 \mathrm{~K}$ in vacuum. X-ray powder diffraction (XRD) studies were carried out on a Bruker instrument, model D8 ADVANCE. The diffractograms were recorded under the following conditions: $\mathrm{Cu} \mathrm{K} \alpha$ radiation; $2 \theta$ range: $5-85^{\circ} ; 2 \theta$ step size: $0.05^{\circ}$; and time per step: $30 \mathrm{~s}$.

STEM-HAADF images were recorded on a JEOL2010F instrument using a $0.5 \mathrm{~nm}$ electron probe at a camera length of $10 \mathrm{~cm}$. The intensity observed in STEM-HAADF images is directly related to the average atomic number $(Z)$ in the region under the electron beam. The difference in atomic number between $\mathrm{Au}(Z=79)$ and the support cations $\left(Z_{\mathrm{Ce}}=58\right.$ and $\left.Z_{\mathrm{Zr}}=40\right)$ is large enough as to guarantee optimum imaging of Au-NPs with diameters even smaller than $1 \mathrm{~nm}$. From the intensity distribution observed in STEM-HAADF images, a simple discrimination of Au-NPs and support can be performed. In any case, the nature of the particles included in the size distributions was further confirmed by X-ray energy dispersive spectroscopy in STEM mode. The JEOL 2010F microscope used had a structural resolution of $0.19 \mathrm{~nm}$ at $200 \mathrm{kV}$ and it was equipped with a STEM-HAADF detector, an EELS spectrometer (GIF2000 Gatan Imaging Filter), and a X-EDS, Oxford Xmax $\left(80 \mathrm{~mm}^{2}\right)$ SDD detector that allows an energy resolution of $0.13 \mathrm{keV}$. To avoid any contact with solvents, samples for Electron Microscopy studies were prepared by depositing small amounts of the catalyst powders directly onto holey-carbon coated $\mathrm{Cu}$ grids. Excess powder was removed from the grids by gentle blowing with a nozzle.

\subsection{Catalytic activity}

Catalytic CO oxidation tests were carried out using in all cases $25 \mathrm{mg}$ of the corresponding as-prepared catalyst, i.e. prior to pretreatment, diluted with $100 \mathrm{mg}$ of quartz and placed in a U-shaped quartz reactor working at atmospheric pressure. The reactant gases were in a $\mathrm{CO}: \mathrm{O}_{2}$ molar ratio of 1:0.6, balanced with inert gas $(\mathrm{He})$ and a total spatial velocity (SV) of $240,000 \mathrm{~cm}^{3} \mathrm{~h}^{-1} \mathrm{~g}^{-1}$. The total flow of the reactants was $100 \mathrm{~cm}^{3} \mathrm{~min}^{-1}$, temperature range: 233-418 K; and heating rate: $10 \mathrm{~K} \mathrm{~min}^{-1}$. The gas flow rates were adjusted by mass flow controllers, model Bronkhorst. The gas composition at the reactor exit was continuously monitored by a mass spectrometer Pfeiffer, model QME-200-D.

\section{Results and discussion}

In contrast to DP methods, incipient wetness impregnations usually involve the use of concentrated metal precursor solutions.
Thus, to identify the optimal $\mathrm{pH}$ conditions for the impregnation step, the speciation of $\mathrm{HAuCl}_{4}$ was studied as a function of its concentration. Although thermodynamic calculations, starting from equilibrium constants determined at the early seventies $[17,20]$, have been previously performed to justify the use of slightly alkaline conditions during DP [41,44], the influence of this key parameter, precursor concentration, has not been yet reported to the best of our knowledge. This is most likely due to the fact that only very diluted $\mathrm{HAuCl}_{4}$ solutions are routinely used in DP.

The equilibrium system formed by $\mathrm{Au}(\mathrm{III}), \mathrm{Cl}^{-}$and $\mathrm{H}^{+}\left(\mathrm{OH}^{-}\right)$is very complex and involves the formation of many tetracoordinated gold species containing different combinations of monodentate ligands $\left(\mathrm{Cl}^{-}, \mathrm{OH}^{-}, \mathrm{H}_{2} \mathrm{O}\right)$. The values of equilibrium constants for different species have been reported in the literature $[20,45,46]$ that can be used to draw speciation curves under a variety of conditions using standard procedures [47]. However, as solutions prepared from $\mathrm{HAuCl}_{4}$ always contain $\mathrm{Au}(\mathrm{III})$ and $\mathrm{Cl}^{-}$in $1: 4 \mathrm{M}$ ratio, the equilibrium composition of these solutions is relatively simple, the only gold species at significant concentrations being those resulting from the successive hydrolysis of the $\left[\mathrm{AuCl}_{4}\right]^{-}$ anion; i.e. $\left[\mathrm{AuCl}_{x}(\mathrm{OH})_{4-x}\right]^{-}$. The results of our study are summarized in Fig. 1. The data obtained for $10^{-3}, 10^{-2}, 10^{-1}$, and $1 \mathrm{M}$ concentrations of the precursor indicate that the increase of the $\mathrm{HAuCl}_{4}$ concentration does not largely change the shape of the distribution curves corresponding to the different hydrolyzed species but gives rise, as major effect, to their progressive shift, as a whole, towards higher $\mathrm{pH}$ values.

To illustrate this, note that for the most diluted solution, $10^{-3} \mathrm{M}$, the $\left[\mathrm{AuCl}_{3}(\mathrm{OH})\right]^{-}$and $\left[\mathrm{AuCl}_{2}(\mathrm{OH})_{2}\right]^{-}$species achieve maxima, with percentages of roughly $70 \%$ and $90 \%$, at $\mathrm{pH}$ values close to 8.5 and 10.5 respectively. At higher gold precursor concentrations, the maxima reach the same percentages but the $\mathrm{pH}$ values at which they peak are significantly higher; 10.5 and 12.5 for a $0.1 \mathrm{M}$ gold concentration; i.e. two units higher in the $\mathrm{pH}$ scale for both species. This shift of the speciation curves with increasing gold precursor concentration makes that the species with the lowest number of attached chlorine atoms, like $\left[\mathrm{AuCl}(\mathrm{OH})_{3}\right]^{-}$, are only present in the diagrams corresponding to very diluted conditions. Thus, the percentage of this species in a $10^{-3} \mathrm{M} \mathrm{HAuCl}_{4}$ solution is close to $90 \%$ under extremely basic conditions but its percentage is quite low or negligible for concentrations above $0.1 \mathrm{M}$. It is also worth noting that, in contrast to data reported in previous works, the totally chlorine-free complex $\left[\mathrm{Au}(\mathrm{OH})_{4}\right]^{-}$is not present in any of the diagrams, even in the cases of the most diluted $\mathrm{HAuCl}_{4}$ solutions.

We can now use these calculated diagrams to select impregnation conditions similar to those characteristic of the DP process. We should recall at this respect that in the DP preparation method the support is contacted with a diluted $\mathrm{HAuCl}_{4}$ solution, typically with a concentration in the order of $10^{-3} \mathrm{M}$, and at constant $\mathrm{pH}$, usually close to 8 . According to the diagram shown in Fig. 1(a), the distribution of species expected for these conditions is that shown as first row in Table 1.

It seems evident that in order to avoid the presence of chlorine in the coordination sphere of gold precursors, the $\left[\mathrm{Au}(\mathrm{OH})_{4}\right]^{-}$complex would be the ideal one for carrying out the impregnation step. However reaching the extreme $\mathrm{pH}$ values needed for this purpose becomes experimentally unfeasible due to the small volumes usually involved in IWI methods.

Note also how, even at very high $\mathrm{pH}$ values, the dechlorination of the initial $\left[\mathrm{AuCl}_{4}\right]^{-}$complex is still rather limited. This result contrasts with others previously reported for Au-DP catalysts which pointed out to the formation of $\mathrm{Au}(\mathrm{OH})_{3}$ precipitates (undesirable for IWI methods) or $\left[\mathrm{Au}(\mathrm{OH})_{4}\right]^{-}$. Even for the lowest $\mathrm{HAuCl}_{4}$ concentrations, the major species in solution at $\mathrm{pH}$ above 12 still contain some coordinated chlorine atoms. 
(a)

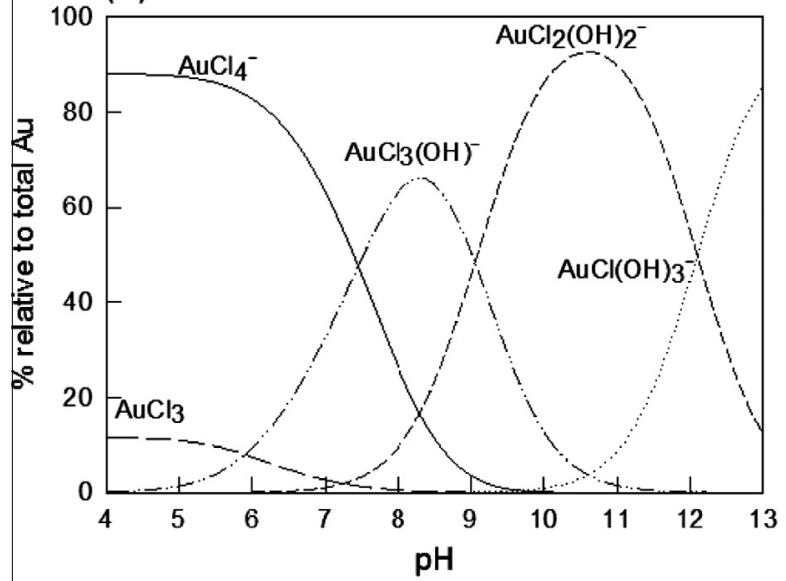

(c)

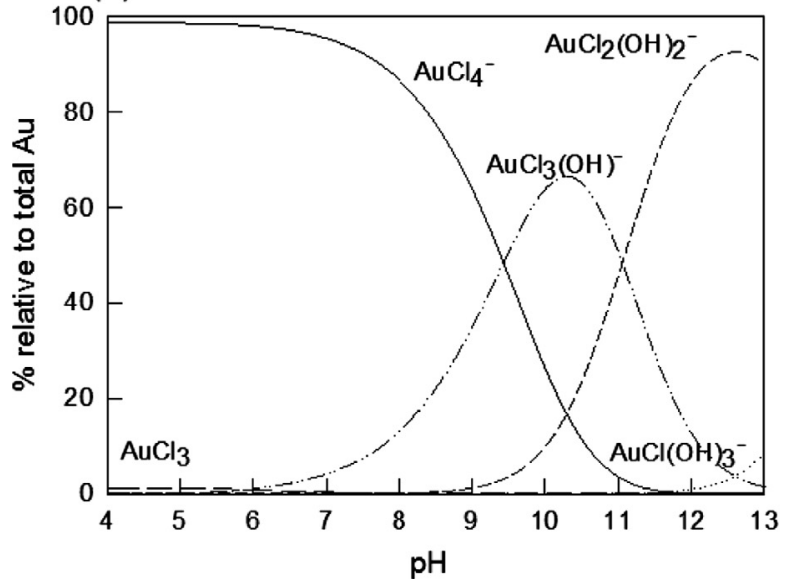

(b)

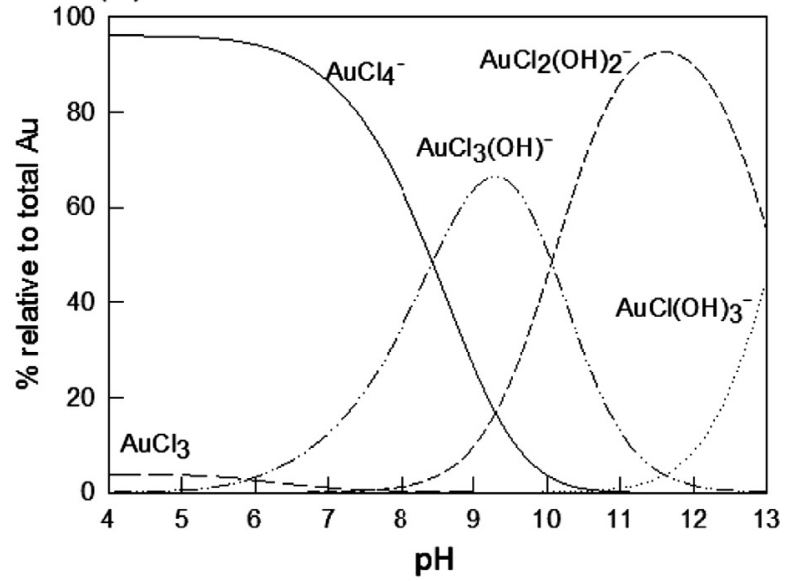

(d)

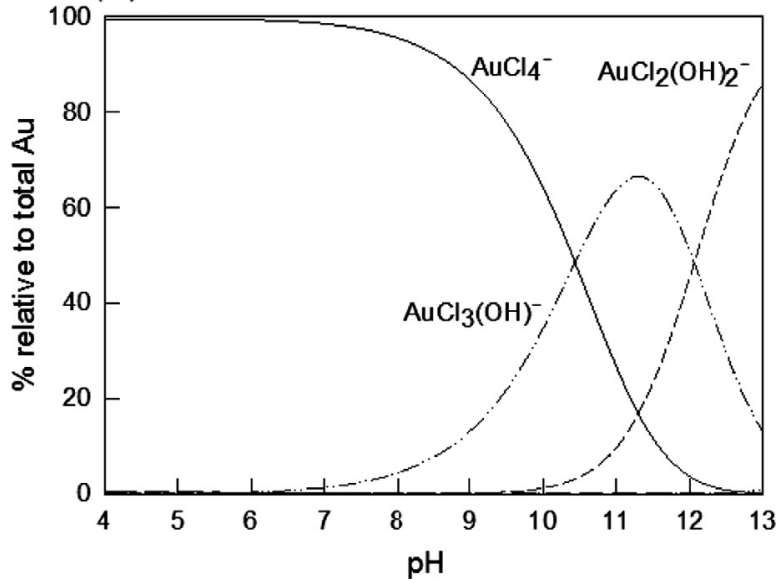

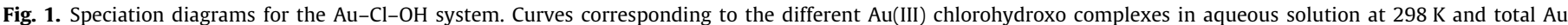

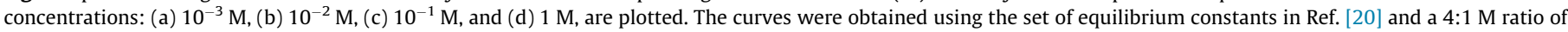
$\mathrm{Cl}^{-}$to $\mathrm{Au}(\mathrm{III})$.

Table 1

Distribution of gold species in solution for different $\mathrm{pH}$ and $\mathrm{HAuCl}_{4}$ concentrations.

\begin{tabular}{|c|c|c|c|c|c|}
\hline Methods & {$\left[\mathrm{HAuCl}_{4}\right](\mathrm{M})$} & $\mathrm{pH}$ & {$\left[\mathrm{AuCl}_{4}\right]^{-}(\%)^{\mathrm{a}}$} & {$\left[\mathrm{AuCl}_{3}(\mathrm{OH})\right]^{-}(\%)^{\mathrm{a}}$} & {$\left[\mathrm{AuCl}_{2}(\mathrm{OH})_{2}\right]^{-}(\%)^{\mathrm{a}}$} \\
\hline DP & $10^{-3}$ & 8 & 25 & 65 & 10 \\
\hline IWI & 1 & 1 & 100 & 0 & 0 \\
\hline ScIWI-8 & 1 & 8 & 95 & 5 & 0 \\
\hline ScIWI-12 & 1 & 12 & 4 & 53 & 43 \\
\hline IWI & $2.5 \cdot 10^{-1}$ & 1 & 100 & 0 & 0 \\
\hline ScIWI-8 & $2.5 \cdot 10^{-1}$ & 8 & 91 & 8.9 & 0.1 \\
\hline ScIWI-12 & $2.5 \cdot 10^{-1}$ & 12 & 1 & 25 & 74 \\
\hline
\end{tabular}

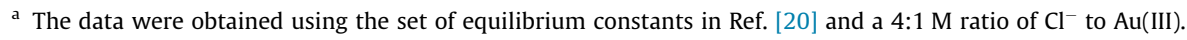

At the concentrations used in IWI, in the order of $1 \mathrm{M}$, a large influence of $\mathrm{pH}$ is observed. Thus, at $\mathrm{pH}$ values employed in conventional IWI, around 1 , the only complex expected in solution is the totally chlorinated one, $\mathrm{AuCl}_{4}^{-}$. This situation does not significantly change up to $\mathrm{pH}$ values below 8 , at which this same complex still accounts for $95 \%$ of total gold in solution. Note however that increasing the $\mathrm{pH}$ in the range $10-12$ results in a significant change in the distribution of species. Thus, at $\mathrm{pH}=12$, the total fraction of the two species with lower chloride ligand content ( $\left[\mathrm{AuCl}_{3}\right.$ $\left.(\mathrm{OH})]^{-}+\left[\mathrm{AuCl}_{2}(\mathrm{OH})_{2}\right]^{-}=96 \%\right)$ accounts for nearly total $\mathrm{Au}(\mathrm{III})$ and, in any case, their total concentration is much higher than that corresponding to the usual DP conditions $\left(\left[\mathrm{AuCl}_{3}(\mathrm{OH})\right]^{-}+\left[\mathrm{AuCl}_{2}\right.\right.$
$\left.\left.(\mathrm{OH})_{2}\right]^{-}=75 \%\right)$. It is specially remarkable the large fraction, $43 \%$, of the more deeply dechlorinated complex, $\left[\mathrm{AuCl}_{2}(\mathrm{OH})_{2}\right]^{-}$, at $\mathrm{pH}=12$.

It is also important to take into account the information available regarding the effect of temperature on the $\left[\mathrm{AuCl}_{4}\right]^{-}$hydrolysis equilibria. Although the literature information concerning this point is not so comprehensive, there are data showing that a moderate increase in the fraction of species with lower chloride content occurs when the temperature is raised up to values below $373 \mathrm{~K}$ $[48,49]$. Therefore, as DP is routinely performed at temperatures close to $353 \mathrm{~K}$, it can be expected that impregnation at $298 \mathrm{~K}$ with concentrated aqueous $\mathrm{HAuCl}_{4}$ solutions stabilized at $\mathrm{pH}=12$ 
should lead to results equivalent to those of DP, at least concerning the size distribution of the gold phase deposited onto the support. Since impregnation methods are widely recognized to allow for a much better control of the total deposited metal quantities, the use of ScIWI may provide a feasible alternative route to, loadingcontrolled, highly dispersed supported gold catalysts.

In order to confirm the hypothesis we have just outlined, $\mathrm{Au} / \mathrm{CZ}$ catalysts were prepared by the ScIWI approach using a $0.25 \mathrm{M}$ $\mathrm{HAuCl}_{4}$ solution stabilized at three increasing $\mathrm{pH}$ values, 1,8 and 12 , by the addition of appropriate amounts of a $0.25 \mathrm{M} \mathrm{NaOH}$ solution. In all cases the preparations were targeted to reach a final 3 wt\% gold metal loading. This loading and the value of the $C Z$ support total pore volume were in fact the factors determining the use of a $0.25 \mathrm{M}$ gold precursor solution. The preparation using $\mathrm{pH}=1$ would illustrate the case of classical IWI, so we will refer it as to $\mathrm{Au} / \mathrm{CZ}-\mathrm{IWI}$ whereas the other two, which account for the effect of increasing fractions of the more dechlorinated gold complexes in the impregnating solution, will be referred as to $\mathrm{Au} / \mathrm{CZ}-\mathrm{ScIWI}-8$ and $\mathrm{Au} / \mathrm{CZ}-\mathrm{ScIWI}-12$, respectively. As a reference, a catalyst was also prepared by the double impregnation method [30], Au/CZ-DIM, with approximately the same metal loading. Additionally, data obtained from a gold supported catalyst previously prepared in our lab using the well-established deposition-precipitation method using urea (Au/CZ-DPU) will be discussed [50].

Fig. 2 shows speciation curves corresponding to the concentration of the $\mathrm{HAuCl}_{4}$ precursor in solution used in the preparation of the catalysts here studied, $0.25 \mathrm{M}$. Although they are similar to that shown in Fig. 1 for $1 \mathrm{M}$, in this case, due to the lower concentration, the hydrolysis of the $\mathrm{HAuCl}_{4}$ precursor is more favored in alkaline media. Thus, larger quantities of the $\left[\mathrm{AuCl}(\mathrm{OH})_{3}\right]^{-}$and $\left[\mathrm{AuCl}_{2}\right.$ $\left.(\mathrm{OH})_{2}\right]^{-}$species are observed at equilibrium (bottom rows in Table 1).

Table 2 gathers final $\mathrm{Au}$ and $\mathrm{Cl}$ contents for all the $\mathrm{Au} / \mathrm{CZ}$ prepared catalysts as well as values of their BET surface areas. Only the $\mathrm{Au} / \mathrm{CZ}-\mathrm{IWI}$ catalyst showed a BET surface area significantly smaller than that of the starting CZ support (59 and $68 \mathrm{~m}^{2} \mathrm{~g}^{-1}$, respectively). The increase of the BET surface area observed with increasing total gold content, in the case of the catalysts prepared by means of impregnation techniques, may be linked to the additional roughness produced by an increasing coverage of the $\mathrm{CZ}$ support by the Au phase. Concerning the final total loading, it is important to highlight that, although the gold concentrations

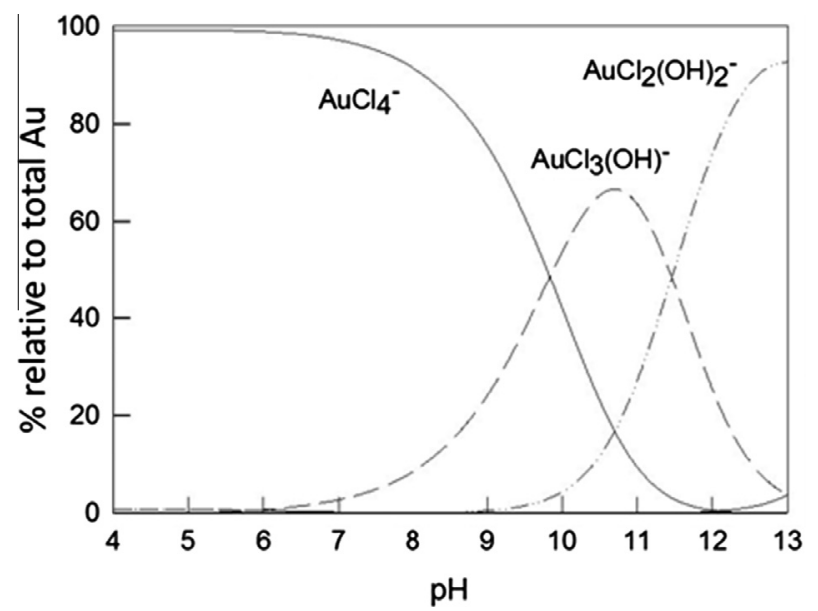

Fig. 2. Speciation diagrams for the $\mathrm{Au}-\mathrm{Cl}-\mathrm{OH}$ system. Curves corresponding to the different $\mathrm{Au}(\mathrm{III})$ chlorohydroxo complexes in aqueous solution at $298 \mathrm{~K}$ and $0.25 \mathrm{M}$ total Au concentration. The curves were obtained using the set of equilibrium constants in Ref. [20] and a $4: 1 \mathrm{M}^{2}$ ratio of $\mathrm{Cl}^{-}$to $\mathrm{Au}(\mathrm{III})$.
Table 2

Surface area, Au loading and residual $\mathrm{Cl}$ content.

\begin{tabular}{llll}
\hline Catalysts & $S_{\text {BET }}\left(\mathrm{m}^{2} \mathrm{~g}^{-1}\right)$ & Au loading $(w t \%)^{\mathrm{a}}$ & $\mathrm{Cl}$ content $(\mathrm{wt} \%)^{\mathrm{b}}$ \\
\hline $\mathrm{CZ}$ & 68 & - & $\mathrm{b} / \mathrm{d}^{\mathrm{c}}$ \\
$\mathrm{Au} / \mathrm{CZ}-\mathrm{IWI}$ & 59 & 1.6 & 0.26 \\
$\mathrm{Au} / \mathrm{CZ}-$ ScIWI-8 & 65 & 2.0 & $\mathrm{~b} / \mathrm{d}^{\mathrm{c}}$ \\
$\mathrm{Au} / \mathrm{CZ}-S c I W I-12$ & 70 & 2.8 & $\mathrm{~b} / \mathrm{d}^{\mathrm{c}}$ \\
$\mathrm{Au} / \mathrm{CZ}-\mathrm{DIM}$ & 62 & 2.1 & $\mathrm{~b} / \mathrm{d}^{\mathrm{c}}$
\end{tabular}

\footnotetext{
a Values determined by ICP-AES

b Values determined by XRF.

c b/d: Below detection limit.
}

in the $\mathrm{HAuCl}_{4}$ impregnating solutions were adjusted to reach a nominal Au loading of $3 \mathrm{wt} \%$, lower values could only be obtained, except in the case of the ScIWI-12 catalyst for which the final loading was only $0.2 \mathrm{wt} \%$ lower than the nominal value (i.e. $93 \%$ of gold in the precursor is used).

Therefore, when the ScIWI approach is used, the fraction of the $\mathrm{Au}$ loading finally deposited onto the $\mathrm{CZ}$ support, relative to the nominal value, increases with $\mathrm{pH}$ in the whole 1-12 range, which is just opposite to that observed in the case of catalysts prepared by DP using either $\mathrm{Na}_{2} \mathrm{CO}_{3}$ or $\mathrm{NaOH}$ as precipitating agent $[24,41,44,51]$. Effectively, it is well established that in order to increase the final Au loading by DP, the $\mathrm{pH}$ value of the solution bearing the support powders must be close to its point of zero charge (PZC). This is a requirement to enhance the attachment of the precursor phase generated in solution to the surface of the corresponding metal oxide support. This constrain becomes unnecessary when impregnation techniques are used. Indeed, the Au loading of the ScIWI sample was very close to the target gold content despite the $\mathrm{pH}$ used to prepare it was much higher than the PZC of the CZ support (ca. 8). This finding is quite relevant since usual yields in the total Au content deposited using Haruta's standard DP methods hardly exceed 60\%, particularly when the target Au loadings are greater than $1 \mathrm{wt} \%[41,44]$. In fact the reported nominal and ICP values for the $\mathrm{Au} / \mathrm{TiO} \mathrm{O}_{2}$ reference catalyst delivered by the World Gold Council are 3 and 1.58 wt\%, respectively [52].

The increase of $\mathrm{Au}$ content with $\mathrm{pH}$ of the impregnating solution (Table 1) and the resulting gold loading data (Table 2) also suggests that the enhanced resistance against the loss of the $\mathrm{Au}$ precursor after washing could be related to a stronger interaction of the $\mathrm{CZ}$ support with the $\left[\mathrm{AuCl}_{2}(\mathrm{OH})_{2}\right]^{-}$or $\left[\mathrm{AuCl}_{3}(\mathrm{OH})\right]^{-}$species than with the $\left[\mathrm{AuCl}_{4}\right]^{-}$complex. At this respect, Nechayev et al. have reported [43], in relation with the preparation of $\mathrm{Au} / \mathrm{Al}_{2} \mathrm{O}_{3}$ catalysts, that the adsorption capability of $\left[\mathrm{AuCl}_{2}(\mathrm{OH})_{2}\right]^{-}$was two orders of magnitude larger than that of $\left[\mathrm{AuCl}_{4}\right]^{-}$.

Concerning the quantities of remnant chloride, these were under the detection limits of analytical techniques, in particular $\mathrm{X}$-ray Fluorescence, in the case of the catalysts prepared by ScIWI and DIM. In contrast, chlorides were still present in a significant amount, $0.26 \mathrm{wt} \%$, in the Au/CZ-IWI catalyst. This is in good agreement with the results of thermodynamic calculations, Table 1. These indicate that at $\mathrm{pH}=1\left[\mathrm{AuCl}_{4}\right]^{-}$is the dominating species in solution. Poor dechlorination of the precursor leads to high chloride levels in the Au precursor phase deposited onto the $\mathrm{CZ}$ support, which cannot be completely removed during the final washing steps of the synthesis procedure.

Moreover, as illustrated in the Scanning Transmission Electron Microscopy High Angle Annular Dark Field (HAADF-STEM) images recorded on the as-prepared $\mathrm{Au} / \mathrm{CZ}$-IWI catalyst, the predominance of this species in solution leads to the formation, during the impregnation step, of extremely large (>100 nm) Au agglomerates, Fig. 3(a). STEM-XEDS (X-ray Energy Dispersive Spectroscopy) analysis recorded on these agglomerates confirms that they are constituted by Au. Pre-treatment at $473 \mathrm{~K}$ for $1 \mathrm{~h}$ under 

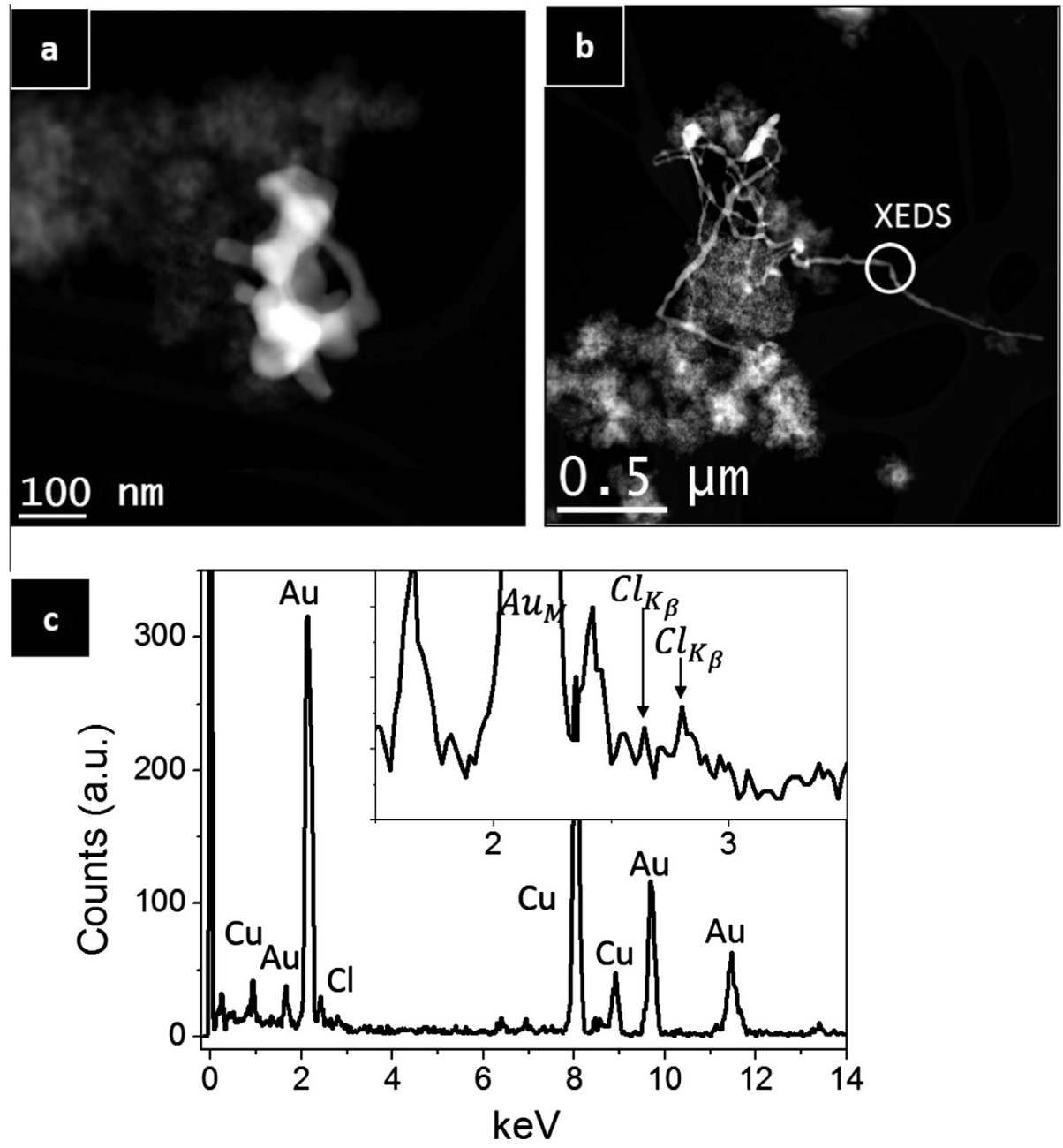

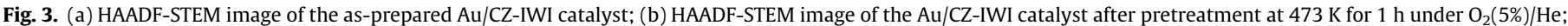
(c) STEM-XEDS analysis performed on the whiskers, indicated by the circle in (b), observed in the Au/CZ-IWI sample pretreated under oxidizing conditions.

$\mathrm{O}_{2}(5 \%) / \mathrm{He}$ of this as-prepared catalyst, induces these agglomerates to grow as micron-lengthen filaments or whiskers, Fig. 3(b). STEM-XEDS analysis performed on the whiskers, as marked in Fig. 3(b), confirmed that these Au structures still retained small quantities of $\mathrm{Cl}$, shown in Fig. 3(c). As expected, a large fraction of $\left[\mathrm{AuCl}_{4}\right]^{-}$in the impregnating solution has led, through polymerization via $\mathrm{Au}-\mathrm{Cl}-\mathrm{Au}$ bridges, to a catalyst with quite poor dispersion, as usually reported for conventional IWI methods [17-21,39].

The Electron Microscopy results reported for the as-prepared $\mathrm{Au} / \mathrm{CZ}-\mathrm{IWI}$ catalyst provide also clues about the presence of large Au structures, due to polymerization, just after classical impregnation, i.e. prior to any further precursor activation pre-treatment. This contrasts with previous proposals that relate the presence of chlorinated species to sintering of Au particles but still suggest that gold agglomeration takes place during the final activation of the deposited precursor phase by calcination pre-treatments [18,39] or, more specifically in the case of catalyst supported on ceria, after reduction in $\mathrm{H}_{2}$ [21].

Fig. 4 gathers the results of the Electron Microscopy studies performed on the rest of $\mathrm{Au} / \mathrm{CZ}$ catalysts. Both STEM-HAADF images and the corresponding particle size distributions obtained from the analysis of a large number of this type of images are shown for the catalysts prepared by the ScIWI and DIM approaches after pretreatment at $473 \mathrm{~K}$ for $1 \mathrm{~h}$ under $\mathrm{O}_{2}(5 \%) / \mathrm{He}$. Curves of cumulative percentage of mass with increasing particle size are also included for each size distribution. Note the large differences existing between the Au/CZ-ScIWI-12 and Au/CZ-ScIWI-8 or $\mathrm{Au} / \mathrm{CZ}$-DIM catalysts. The former, Fig. 4(a) shows a very narrow particle size distribution with a pretty small average diameter value, $0.9 \mathrm{~nm}$. Moreover, all the particles identified in the STEM-HAADF images of this catalyst showed diameters below $1.5 \mathrm{~nm}$. In contrast, the particle size distributions of the other two catalysts are very broad, with particles ranging in size from below the nanometer up to nearly $15 \mathrm{~nm}$, in the case of $\mathrm{Au} / \mathrm{CZ}$ ScIWI-8, Fig. 4(b), or 20 nm, in Au/CZ-DIM, Fig. 4(c). Consequently, the total gold dispersion for the Au/CZ-ScIWI-12 catalyst results as high as $89 \%$, whereas it reaches only about $15 \%$ in the other two. Moreover it is also important to state the large differences between the mass distributions of these catalysts. In the Au/CZ-ScIWI-12 sample, $100 \%$ of the gold metal atoms are part of the particles with size below $1.5 \mathrm{~nm}$, i.e. within the size range widely admitted as that corresponding to the particles presenting catalytic activity. In the case of the $\mathrm{Au} / \mathrm{CZ}$-ScIWI- 8 catalyst, only $10 \%$ of the total gold atoms are involved in particles with a size below $5 \mathrm{~nm}$, another $10 \%$ is forming part of particles in the size range between 5 and $10 \mathrm{~nm}$ and about $80 \%$ is embedded within particles with size larger than $10 \mathrm{~nm}$; i.e. most of the gold mass takes part of poorly active gold nanoparticles. Similar comments can be stated about the catalyst prepared by the DIM method. In this latter case the mass distribution concentrates even more on the fraction of gold 

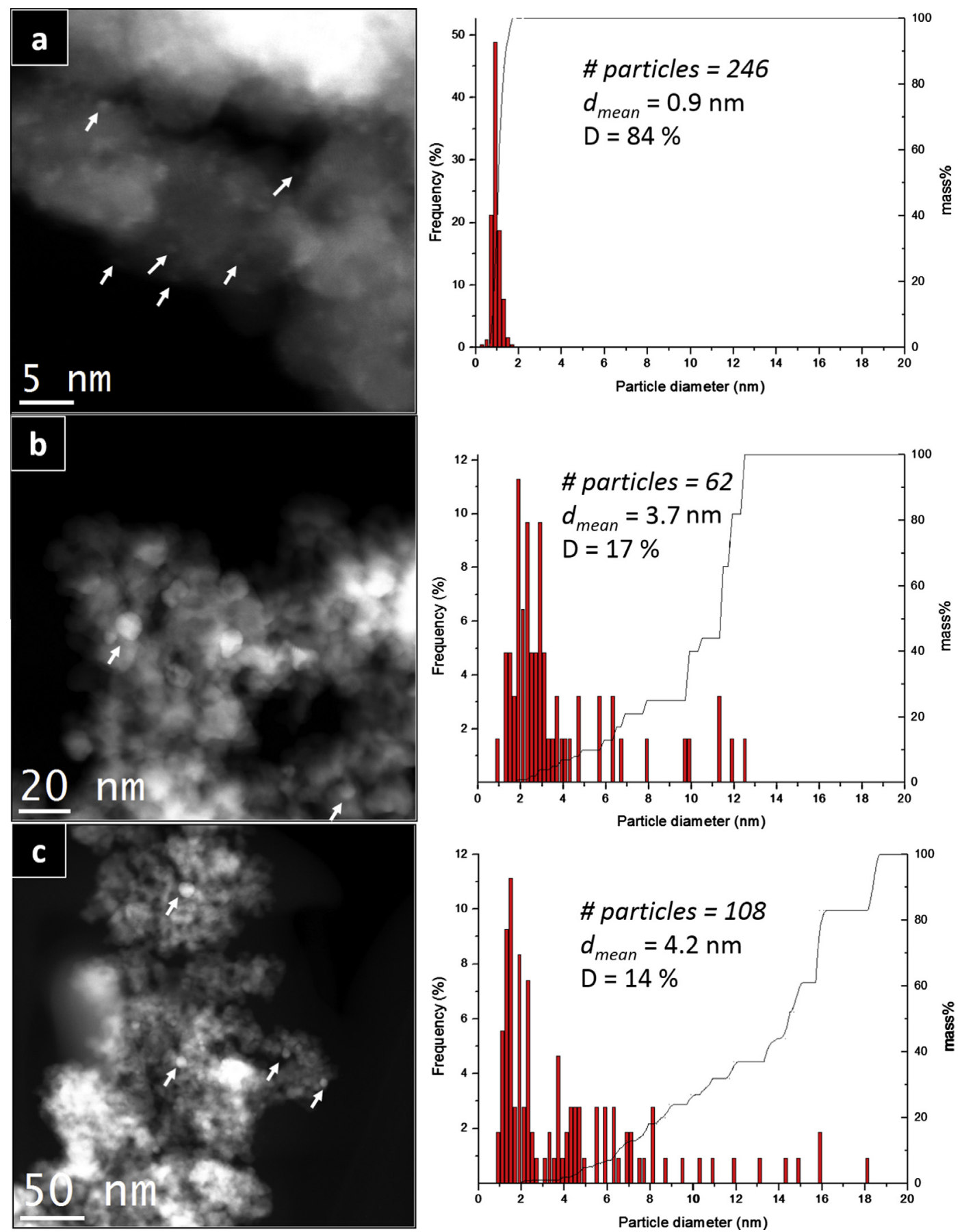

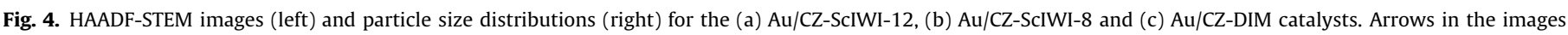

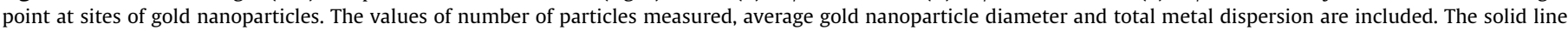
plots correspond to the cumulative percentage of $\mathrm{Au}$ atoms as a function of particle size.

particles of very large size. Thus, only about $5 \%$ of the total gold atoms take part of particles smaller than $5 \mathrm{~nm}$, whereas $77 \%$ of them belong to particles larger than $10 \mathrm{~nm}$.

The Electron Microscopy studies commented above make clear the very large influence of preparation conditions on the final particle size distribution and, at the same time, the possibility to prepare catalysts with a very highly dispersed gold phase by impregnation when the nature of the species present in the impregnating solution is adequately tailored. In fact, the total dispersion of the Au/CZ-ScIWI-12 catalyst reported here is even higher than that of similar Au catalysts, prepared on the same CZ-oxide support, by DP methods [50,53].

The results of the STEM-HAADF study were further consistent with those obtained at macroscopic level by XRD analysis, Fig. 5. In this figure the diagrams for the different $\mathrm{Au} / \mathrm{CZ}$ catalysts are shown, including an enlargement of the $2 \theta$ region corresponding to the two most intense Au maxima, $38^{\circ}$ (111) and $42^{\circ}$ (200), for a better appreciation of the characteristics of the dispersed metallic phase. As expected, all the diagrams show the diffraction peaks attributable to the $\mathrm{CZ}$ mixed oxide [54] used as support. In 


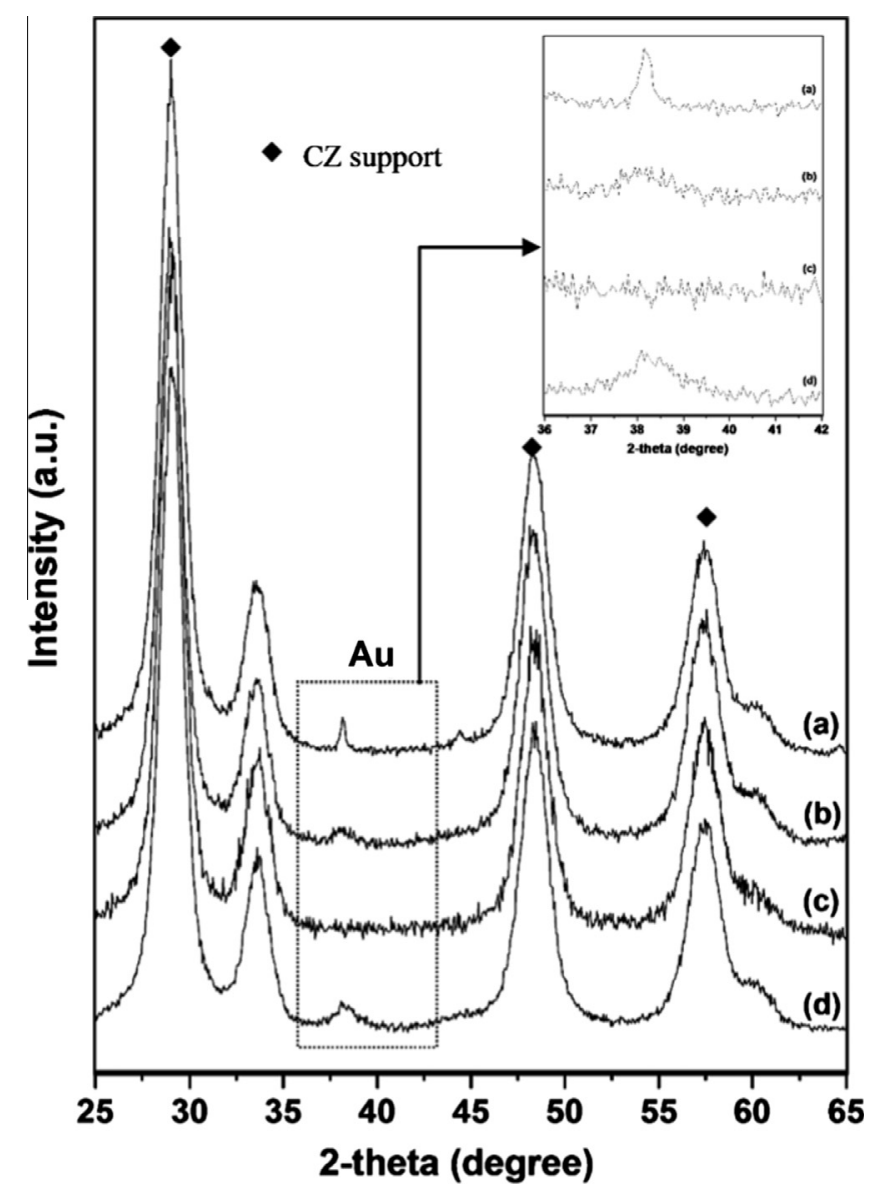

Fig. 5. XRD diagrams of the Au/CZ catalysts: (a) IWI, (b) ScIWI-8, (c) ScIWI-12 and (d) DIM. An enlargement of the $2 \theta$ range in which fcc gold peaks appear is shown as inset.

the diagram corresponding to the Au/CZ-IWI catalyst the fcc Au (111) diffraction peak, at $\sim 38.2^{\circ}$, is particularly intense and narrow, Fig. 5(a), this being in very good agreement with the severe sintering observed in the STEM-HAADF images, Fig. 3. Note that this peak is also detected in the diagrams of the Au/CZ-ScIWI-8 and $\mathrm{Au} / \mathrm{CZ}$-DIM catalysts but it is not observed for the $\mathrm{Au} / \mathrm{CZ}-$ ScIWI-12 sample, Fig. 5(b) and (d) respectively. The absence of this peak in the diagram of the $\mathrm{Au} / \mathrm{CZ}-\mathrm{ScIWI}-12$ catalyst, in spite of being the one with the highest Au loading, agrees perfectly well with the characteristics of the particle size distribution obtained by Electron Microscopy, with all the particles below $1.5 \mathrm{~nm}$ in diameter.

Finally, as a functional prove of the suitability of the preparation method here reported, the catalytic activity in the CO oxidation reaction of the $\mathrm{Au} / \mathrm{CZ}-\mathrm{ScIWI}-12$ catalyst was evaluated comparatively with that of the $\mathrm{Au} / \mathrm{CZ}-\mathrm{IWI}$ and $\mathrm{Au} / \mathrm{CZ}$-DIM catalysts. The catalytic reaction was carried out from $233 \mathrm{~K}$ to $418 \mathrm{~K}$. Thus, Fig. 6 shows the light-off curves of these samples as well as that corresponding to $\mathrm{Au} / \mathrm{CZ}-\mathrm{ScIWI}-8$ to illustrate the strong influence of $\mathrm{pH}$ on the results of the synthesis.

Note first the large difference existing between the catalyst prepared by classical impregnation, Au/CZ-IWI, curve (a), and those prepared by controlling the speciation of gold complexes existing in the impregnating solution, $\mathrm{Au} / \mathrm{CZ}$-ScIWI catalysts, curves (b) and (d). Thus, whereas the former does not show any detectable CO conversion within the temperature range plotted in Fig. 6, the catalysts prepared using the ScIWI approach present, as shown in Table 3 , characteristic light-off temperatures $\left(T_{50}\right.$, i.e.

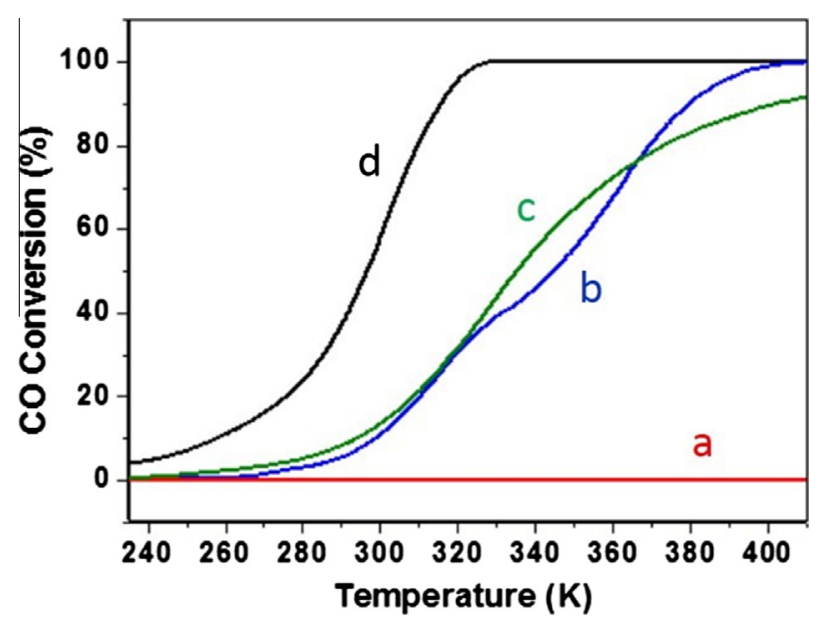

Fig. 6. Light-off curves for $\mathrm{CO}$ oxidation of the $\mathrm{Au} / \mathrm{CZ}$ catalysts: $\mathrm{Au} / \mathrm{CZ}-\mathrm{IWI}(\mathrm{a}), \mathrm{Au} /$ CZ-ScIWI-8 (b), Au/CZ-DIM (c) and Au/CZ-SCIWI-12 (d).

Table 3

Characteristic $\mathrm{CO}$ conversion temperatures for the different $\mathrm{Au} / \mathrm{CZ}$ catalysts.

\begin{tabular}{|c|c|c|c|}
\hline Catalysts & $T_{10}(\mathrm{~K})^{\mathrm{a}}$ & $T_{50}(\mathrm{~K})^{\mathrm{a}}$ & $T_{100}(\mathrm{~K})^{\mathrm{a}}$ \\
\hline $\mathrm{CZ}$ & 547 & 636 & 801 \\
\hline $\mathrm{Au} / \mathrm{CZ}-\mathrm{IWI}$ & 658 & 774 & $>1050$ \\
\hline $\mathrm{Au} / \mathrm{CZ}-\mathrm{ScIWI}-8$ & 294 & 336 & 406 \\
\hline $\mathrm{Au} / \mathrm{CZ}-\mathrm{ScIWI}-12$ & 255 & 296 & 329 \\
\hline $\mathrm{Au} / \mathrm{CZ}-\mathrm{DIM}$ & 293 & 345 & $>410$ \\
\hline $\mathrm{Au} / \mathrm{CZ}-\mathrm{DPU}^{\mathrm{b}}$ & 265 & 302 & 367 \\
\hline
\end{tabular}

a Temperatures at which conversion of $10 \%, 50 \%$ or $100 \%$ are reached.

b Data taken from Ref. [50].

the temperature at which CO conversion reaches 50\%) of just $336 \mathrm{~K}, \mathrm{Au} / \mathrm{CZ}-\mathrm{ScIWI}-8$, and $296 \mathrm{~K}, \mathrm{Au} / \mathrm{CZSCIWI}-12$. Outstandingly, the $T_{50}$ value of the $\mathrm{Au} / \mathrm{CZ}$-ScIWI-12 sample is below room temperature and, also important, 40 degrees below that of the catalyst prepared at $\mathrm{pH}=8$. The superior activity of the $\mathrm{Au} / \mathrm{CZ}-\mathrm{ScIWI}-12$ catalyst is also demonstrated by the fact that it shows significant CO conversion (10\%) at temperatures below $273 \mathrm{~K}$, roughly $253 \mathrm{~K}$. Note as well that it completes total CO conversion at just $329 \mathrm{~K}$. The catalytic activity of the $\mathrm{Au} / \mathrm{CZ}-\mathrm{ScIWI}-8$ catalyst resembles quite closely that of $\mathrm{Au} / \mathrm{CZ}$-DIM, curve (c), which shows a $T_{100}$ value of about $345 \mathrm{~K}$. Au/CZ-ScIWI-8 does not show measurable CO conversion at $253 \mathrm{~K}$ and does only complete $\mathrm{CO}$ oxidation, under the assayed mass flow conditions, above $400 \mathrm{~K}$.

It is worth commenting that the catalytic performance of the material prepared by ScIWI at optimum $\mathrm{pH}$ conditions, $\mathrm{Au} / \mathrm{CZ}$ ScIWI-12, improves even that of a catalyst prepared on the same support by conventional DPU method, Au/CZ-DPU [50] (Table 3). The catalyst prepared by conventional impregnation, containing very large Au agglomerates and whiskers, results inactive, behaving in fact even slightly worse than a bare ceria-zirconia support, Table 3, most likely due to the poisoning effect of residual chlorides, Table 2, on the redox properties of ceria-zirconia [55].

\section{Conclusions}

In summary, it has been proven that on the basis of a priori thermodynamic calculations and by properly controlling the species distribution of $\mathrm{HAuCl}_{4}$ solutions, by means of $\mathrm{pH}$, is possible to avoid Au sintering during impregnation and preparing ceria-zirconia supported gold catalysts with dispersions and CO oxidation activity as high or even better than that of those obtained by the more complex DP method. Interestingly, the use of the 
rational approach devised by us, ScIWI, allows minimizing losses of the $\mathrm{HAuCl}_{4}$ precursor and, therefore, a highly efficient usage of such an expensive material. Also important, it avoids the use of temperatures well above room temperature, as those involved in DP, during catalyst preparation or the use of gold-organocomplexes, as it was the case in previous alternative incipient wetness impregnation proposals.

Simple equipment requirements, energy saving, efficient usage of gold and easy scaling-up make of ScIWI a synthesis technique not only very interesting from a laboratory point of view but also for its use at industrial levels.

\section{Acknowledgments}

The authors acknowledge financial resources from the European Union Seventh Framework Programme under Grant Agreement 312483 - ESTEEM2 (Integrated Infrastructure Initiative - I3), from MICINN/FEDER Project IMAGINE (Ref: CSD2009-00013), MEC and MINECO Projects CTQ2012-37821-C02-02 and MAT201340823-R, and Junta de Andalucía Grant P10-FQM-6766 and FQM110, FQM137, FQM334 groups. Electron Microscopy data were recorded at SCCyT-UCA. The ceria-zirconia sample used as support was kindly donated by Grace Davison.

\section{References}

[1] M. Haruta, T. Kobayashi, H. Sano, N. Yamada, Chem. Lett. 16 (1987) 405.

[2] M. Haruta, H. Kageyama, N. Kamijo, T. Kobayashi, F. Delannay, in: T. Inui (Ed.) Studies in Surface Science and Catalysis Successful Design of Catalysts Future Requirements and Development, Proceedings of the Worldwide Catalysis Seminars, July, 1988, on the Occasion of the 30th Anniversary of the Catalysis Society of Japan, Elsevier, 1989, p. 33.

[3] M. Haruta, N. Yamada, T. Kobayashi, S. Iijima, J. Catal. 115 (1989) 301.

[4] G.C. Bond, C. Louis, D.T. Thompson, Catalysis by Gold, in: G.J. Hutchings (Ed.), Imperial College Press, London, 2006.

[5] T. Takei, T. Akita, I. Nakamura, T. Fujitani, M. Okumura, K. Okazaki, J. Huang, T. Ishida, M. Haruta, in: B.C. Gates, F.C. Jentoff (Eds.), Advances in Catalysis, Academic Press, 2013, p. 1.

[6] A.S.K. Hashmi, G.J. Hutchings, Angew. Chem. Int. Ed. 45 (2006) 7896.

[7] S. Galvagno, G. Parravano, J. Catal. 55 (1978) 178.

[8] G.C. Bond, P.A. Sermon, Gold Bull. 6 (1973) 102.

[9] P.A. Sermon, G.C. Bond, P.B. Wells, J. Chem. Soc., Faraday Trans. 1: Phys. Chem. Condens. Phases 75 (1979) 385

[10] G. Bond, Gold Bull. 41 (3) (2008) 235.

[11] G. Parravano, J. Catal. 18 (1970) 320.

[12] S.D. Lin, M. Bollinger, M.A. Vannice, Catal. Lett. 17 (1993) 245.

[13] M. Turner, V.B. Golovko, O.P.H. Vaughan, P. Abdulkin, A. Berenguer-Murcia, M.S. Tikhov, B.F.G. Johnson, R.M. Lambert, Nature 454 (2008) 981.

[14] M. Valden, X. Lai, D.W. Goodman, Science 281 (1998) 1647.

[15] G.C. Bond, Catal. Rev. 41 (1999) 319.

[16] M. Haruta, J. New Mater. Electrochem. Syst. 7 (2004) 163.
[17] F. Farges, J.A. Sharps, G.E. Brown Jr., Geochim. Cosmochim. Acta 57 (1993) 1243.

[18] B.S. Uphade, M. Okumura, S. Tsubota, M. Haruta, Appl. Catal. A - Gen. 190 (2000) 43.

[19] M. Hargittai, A. Schulz, B. Réffy, M. Kolonits, J. Am. Chem. Soc. 123 (2001) 1449.

[20] I.V. Mironov, E.V. Makotchenko, J. Solution Chem. 38 (2009) 725.

[21] S.A.C. Carabineiro, A.M.T. Silva, G. Dražić, P.B. Tavares, J.L. Figueiredo, Catal. Today 154 (2010) 293.

[22] A.S.K. Hashmi, Chem. Rev. 107 (2007) 3180.

[23] A.S.K. Hashmi, M.C. Blanco, E. Kurpejović, W. Frey, J.W. Bats, Adv. Synth. Catal. 348 (2006) 709.

[24] S.J. Lee, A. Gavriilidis, J. Catal. 206 (2002) 305.

[25] Q. Xu, K.C.C. Kharas, A.K. Datye, Catal. Lett. 85 (2003) 229.

[26] S.-H. Wu, B.-Q. Li, W.-P. Huang, S.-M. Zhang, J. Shi, X.-C. Zheng, React. Kinet, Catal. Lett. 78 (2003) 49.

[27] L. Delannoy, N. El Hassan, A. Musi, N.N. Le To, J.-M. Krafft, C. Louis, J. Phys. Chem. B 110 (2006) 22471.

[28] W.C. Li, M. Comotti, F. Schüth, J. Catal. 237 (2006) 190.

[29] J.C. Soares, M. Hall, M. Cristofolini, M. Bowker, Catal. Lett. 109 (2006) 103.

[30] M. Bowker, A. Nuhu, J.M.C. Soares, Catal. Today 122 (2007) 245.

[31] H.Y. Tsai, Y. Lin, W.T. Fu, S.D. Lin, Gold Bull. 40 (3) (2007) 184.

[32] C. Baatz, N. Decker, U. Prübe, J. Catal. 258 (2008) 165.

[33] A. Hugon, N.E. Kolli, C. Louis, J. Catal. 274 (2010) 239.

[34] J.M. Fisher, Gold Bull. 36 (2003) 155.

[35] G. Steinhauser, J. Evers, S. Jakob, T.M. Klapotke, G. Oehlinger, Gold Bull. 41 (2008) 305.

[36] S.A.C. Carabineiro, S.S.T. Bastos, J.J.M. Órfão, M.F.R. Pereira, J.J. Delgado, J.L. Figueiredo, Appl. Catal. A - Gen. 381 (2010) 150.

[37] N.K. Gamboa-Rosales, J.L. Ayastuy, M.P. Gonzalez-Marcos, M.A. GutierrezOrtiz, Catal. Today 176 (2011) 63.

[38] A.I. Kozlov, A.P. Kozlova, H. Liu, Y. Iwasawa, Appl. Catal. A - Gen. 182 (1999) 9.

[39] H.S. Oh, J.H. Yang, C.K. Costello, Y.M. Wang, S.R. Bare, H.H. Kung, M.C. Kung, J. Catal. $210(2002) 375$

[40] D.W. Goodman, Catal. Lett. 111 (2006) 15.

[41] F. Moreau, G.C. Bond, A.O. Taylor, J. Catal. 231 (2005) 105.

[42] J.M. Gatica, E. Del Rio, J.J. Calvino, J.C. Hernández Garrido, M.G. Basallote, M.J. Fernandez, J.A. Pérez-Omil, M.A. Cauqui, S.P.a.T. Office.201300670, 2013.

[43] Y.A. Nechayev, N.V. Nikolenko, Geochem. Int. 23 (1986) 32.

[44] A. Wolf, F. Schüth, Appl. Catal. A - Gen. 226 (2002) 1.

[45] J.A. Peck, C.D. Tait, B.I. Swanson, G.E. Brown, Geochim. Cosmochim. Acta 55 (1991) 671.

[46] L. Almgren, Acta Chem. Scand. 25 (1971) 3713.

[47] L. Alderighi, P. Gans, A. Ienco, D. Peters, A. Sabatini, A. Vacca, Coord. Chem. Rev. 184 (1999) 311.

[48] P.J. Murphy, G. Stevens, M.S. LaGrange, Geochim. Cosmochim. Acta 64 (2000) 479.

[49] Belevant Vi, G.R. Kolonin, Ryakhovs Sk, Zh. Neorg. Khim. 17 (1972) 2492.

[50] E. del Río, G. Blanco, S. Collins, M. Haro, X. Chen, J. Delgado, J. Calvino, S. Bernal, Top. Catal. 54 (2011) 931.

[51] R.J.H. Grisel, P.J. Kooyman, B.E. Nieuwenhuys, J. Catal. 191 (2000) 430.

[52] M. Haruta, S. Tsubota, Gold Bull. 36 (2003) 24.

[53] M. Lopez-Haro, J.J. Delgado, J.M. Cies, E. del Rio, S. Bernal, R. Burch, M.A. Cauqui, S. Trasobares, J.A. Perez-Omil, P. Bayle-Guillemaud, J.J. Calvino, Angew. Chem. Int. Ed. 49 (2010) 1981.

[54] M. López-Haro, J.A. Pérez-Omil, J.C. Hernández-Garrido, S. Trasobares, A.B. Hungría, J.M. Cíes, P.A. Midgley, P. Bayle-Guillemaud, A. Martínez-Arias, S. Bernal, J.J. Delgado, J.J. Calvino, ChemCatChem 3 (2011) 1015.

[55] S. Bernal, J.J. Calvino, G.A. Cifredo, J.M. Gatica, J.A. Pérez Omil, A. Laachir, V. Perrichon, in: A. Frennet, J.-M. Bastin (Eds.), Studies in Surface Science and Catalysis, Elsevier, 1995, p. 419. 